\title{
Pore pressure distribution in the focal region of the 2008 M7.2 Iwate-Miyagi Nairiku earthquake
}

\author{
Keisuke Yoshida ${ }^{*}$, Akira Hasegawa ${ }^{1}$, Tomomi Okada ${ }^{1}$, Hiroaki Takahashi ${ }^{2}$, Masahiro Kosuga ${ }^{3}$, Takaya Iwasaki ${ }^{4}$, \\ Yoshiko Yamanaka ${ }^{5}$, Hiroshi Katao ${ }^{6}$, Yoshihisa lio ${ }^{6}$, Atsuki Kubo ${ }^{7}$, Takeshi Matsushima ${ }^{8}$, Hiroki Miyamachi ${ }^{9}$ \\ and Youichi Asano ${ }^{10}$
}

\begin{abstract}
The pore fluid pressure distribution in the focal region of the 2008 Iwate-Miyagi Nairiku earthquake was investigated through an analysis of the diversity of focal mechanisms. We inverted stress orientations and focal mechanisms directly from P-wave polarity data obtained from a dense aftershock observation network and other temporarily and routinely operated stations. The estimated stress orientation is consistent with that typical of NE Japan. Specifically, the $\sigma 1$ axis is oriented WNW-ESE nearly parallel to plate convergence, and the $\sigma 3$ axis is nearly vertical, consistent with a reverse-faulting stress regime, with some exceptions in the central part of the aftershock area. We obtained 2,497 well-determined focal mechanisms whose average number of P-wave polarity data is more than 70 . The spatial distribution of pore fluid pressure was estimated by using the obtained orientations of the principal stresses and earthquake faults. The pore pressure ratio for each earthquake fault was calculated under the assumption that reduced frictional strength was caused by pore fluid pressure. The results showed that the diversity of the focal mechanisms here obtained requires high pore fluid pressures at many of the earthquake faults in the focal region. The spatial pattern of pore pressure ratio shows that areas of higher pore pressure ratio are distributed around the large coseismic slip area near Kurikoma volcano. Immediately beneath these high pore pressure areas, there exists a distinct seismic low-velocity zone that continues down to the mantle wedge below. These observations suggest that crustal fluids supplied from the mantle wedge have contributed to producing high pore pressures and to lowering the frictional strengths of those faults. Crustal fluids may also have contributed to generating the mainshock rupture.
\end{abstract}

Keywords: 2008 Iwate-Miyagi Nairiku earthquake; NE Japan; Focal mechanism; Pore fluid pressure; Stress tensor inversion

\section{Correspondence/Findings}

\section{Introduction}

The 2008 Iwate-Miyagi Nairiku earthquake occurred in the central part of NE Japan along the eastern margin of the Ou Backbone Range. Just after this earthquake, a dense aftershock observation network was deployed in and around the focal region by the Group for aftershock observations of the Iwate-Miyagi Nairiku earthquake of 2008. High-resolution analysis of the distribution and focal mechanisms of the aftershocks showed that the earthquake sequence involved rupturing on conjugate reverse faults dipping both to the WNW and ESE (Okada et al. 2012).

\footnotetext{
* Correspondence: k-yoshida@aob.gp.tohoku.ac.jp

${ }^{1}$ Research Center for Prediction of Earthquakes and Volcanic Eruptions, Graduate School of Science, Tohoku University, 6-6 Aza-Aoba, Aramaki, Aoba-ku, Sendai 980-8578, Japan

Full list of author information is available at the end of the article
}

Okada et al. (2010) performed a regional-scale seismic tomography and found that distinct seismic low-velocity zones are continuously distributed from the mantle wedge to the lower crust immediately below the focal region of this event. This low-velocity zone links to the inclined lowvelocity zone in the mantle wedge, which is interpreted as the upwelling flow portion of the mechanically induced secondary convection in the mantle wedge (e.g., Hasegawa and Nakajima 2004).

Spatial heterogeneity of frictional strength caused by varying fluid overpressure allows differently oriented fault planes to satisfy the failure criterion. Conversely, the diversity of focal mechanisms might be used to investigate spatial heterogeneity of frictional strengths (e.g., Rivera and Kanamori 2002).

The diversity of focal mechanism is also produced by a spatial heterogeneity of stress. Stress orientations

\section{实}


can be estimated independently to some extent by stress tensor inversions of focal mechanisms or P-wave polarities (e.g., Gephart and Forsyth 1984; Michael 1987) under the assumption of uniform stress orientation in the volume from which the data are taken. In fact, stress tensor inversions have revealed that trench-normal compressive stresses tend to dominate over broad regions of NE Japan (e.g., Terakawa and Matsu'ura 2010; Yoshida et al. 2012).

In this study, we thus assume that stress in the focal region is uniform, and the diversity of focal mechanisms is interpreted to show spatial heterogeneity of frictional strength caused by varying degrees of fluid overpressure. Nevertheless, we cannot fully assess the validity of this assumption because we cannot estimate magnitudes of stress. However, spatial variation of frictional strength is suggested from the existence of distinct seismic lowvelocity zones below the focal region, which are probably caused by aqueous fluids supplied from the underlying mantle wedge. Thus, we assume here that frictional strengths, rather than stresses, are mostly responsible for the diversity of focal mechanisms. Later, we perform calculations and discussions assuming spatial heterogeneity of stress.

We can accurately determine focal mechanisms of small earthquakes by using P-wave polarities if a dense network of seismic stations is available. In this study, we estimate focal mechanisms and stress fields in the focal region of the 2008 Iwate-Miyagi Nairiku earthquake using P-wave polarity data obtained from the very dense seismic networks for aftershock observation and other surrounding stations (Okada et al. 2012). From these, we then estimate spatial variation of pore fluid overpressure in the focal region.

\section{Data and methods}

We estimated focal mechanisms and the stress field simultaneously using P-wave polarity data. A great number of good quality data were obtained due to the dense aftershock observation network composed of 128 stations deployed just after the mainshock and 23 permanent stations by Tohoku University, the National Research National Institute for Earth Science and Disaster Prevention (NIED), and the Japan Meteorological Agency (JMA). Furthermore, a temporary seismic network composed of 52 stations had been deployed in and around the focal region by the Japan Nuclear Energy Safety Organization (JNES) since 6 months before the mainshock occurrence. We used P-wave polarity data from these temporary networks and from other routinely operated stations in surrounding areas.

First, we manually picked P-wave polarities for aftershocks relocated by Okada et al. (2012), who precisely determined aftershock hypocenters by using the temporary seismic stations. The hypocenters and the seismic stations used are shown in Additional file 1: Figure S1. Then, we applied the stress-tensor inversion code MOTSI, improved by Abers and Gephart (2001) for simultaneous inversions of focal mechanisms and stress field, to these $\mathrm{P}$-wave polarity data. In the inversions, we assumed that (1) events occurred along fault planes having various strikes and dips, (2) slip occurred in the direction of maximum resolved shear stress on those planes, and (3) the stress field was uniform in the volume from which the data were taken. We expected that direct inversions of P-wave polarities would decrease the uncertainties of slip vectors of focal mechanisms. Hypocenters relocated by Okada et al. (2012) and the seismic velocity structure used in routine processing at Tohoku University (Hasegawa et al. 1978) were adopted. We used events with more than 30 P-wave polarities. Pore fluid pressure at each earthquake fault plane was estimated as follows. The static frictional coefficient $\mu$ on a fault plane whose unit normal vector is $\vec{n}=\left(n_{1}, n_{2}, n_{3}\right)$ in the principal stress coordinate system was expressed as

$$
\mu=\frac{\sqrt{K_{2}-K^{2}}}{K+S-c(2 S+1) / 2},
$$

where $K=n_{1}^{2}+n_{2}^{2} R ; K_{2}=n_{1}^{2}+n_{2}^{2} R^{2} ; R=(\sigma 2-\sigma 3) /$ $(\sigma 1-\sigma 3) ; c=2 P /(\sigma 1+\sigma 3) ; S=\sigma 3 /(\sigma 1-\sigma 3) ;$ and $\sigma 1$, $\sigma 2$, and $\sigma 3$ are principal stresses with $\sigma 1>\sigma 2>\sigma 3$, and $P$ is pore fluid pressure (Rivera and Kanamori 2002). Cohesion is ignored in the equation. From the stress tensor inversions, $\vec{n}$ was determined for each earthquake fault, and $R$ was also determined. Using the pore pressure ratio $\lambda_{v}=P / \sigma_{v}$ and the vertical unit vector $\vec{m}=\left(m_{1}, m_{2}, m_{3}\right)$ in the principal stress coordinate system, we rewrite Equation 1 as

$$
\lambda_{v}=\left(\frac{P}{\sigma_{n}}\right)\left(\frac{\sigma_{n}}{\sigma_{v}}\right)=\left(1-\frac{\sqrt{K_{2}-K^{2}}}{\mu(K+S)}\right)\left(\frac{K+S}{L+S}\right),
$$

where $L=m_{1}^{2}+m_{2}^{2} R, \quad \sigma_{n}$ is the normal stress acting on the plane, and $\sigma_{v}$ is the normal stress acting on the horizontal plane. Here, we assumed $\mu=0.6$ (Byerlee 1978), which means that smaller apparent frictional coefficients are caused by fluid overpressure. Thus, $\lambda_{v}$ can be calculated from Equation 2, if $S$ is given. $S$ represents the ratio between differential stress and absolute stress. For example, $S \approx 0.47$ corresponds to the critical stress state in which the shear stress acting on an optimally oriented fault is equal to the frictional strength without pore fluid pressure. We could constrain $S$ to be larger than this value, but we no longer know the actual value of $S$ in the crust. Hence, we cannot determine the absolute value of $\lambda_{v}$ unless some assumption is made. Here, we chose $S=$ 1.0, referring to Rivera and Kanamori (2002), based on the results of German KTB and the Cajon deep holes 
(Brudy et al. 1987; Zoback and Healy 1992). Other values of $S$ were also used for comparison. Using the calculated value for each earthquake fault, we investigated the spatial distribution of the pore pressure ratio $\lambda_{v}$. Similar methods were used by Terakawa et al. (2010), Terakawa et al. (2012), and Leclère et al. (2013). The advantage of the present approach is that we need not assume the full stress tensor even under the condition of constant $S$.

\section{Results}

We applied the stress tensor inversion method to the data in the entire study area. Estimated orientations of $\sigma 1$ and $\sigma 3$ axes are shown in Figure 1a. Their $68 \%$ and 95\% confidence regions are shown in Additional file 2: Figure S2a. Figure 1a shows that the $\sigma 1$ axis is oriented WNW-ESE parallel to the plate convergence and that the $\sigma 3$ axis is nearly vertical, showing a reverse-faulting stress regime. This stress orientation is consistent with previous estimates in NE Japan (e.g., Hasegawa et al. 1994; Terakawa and Matsu'ura 2010; Yoshida et al. 2012). In addition to stress orientations, focal mechanisms and pore pressure ratios on each fault plane were estimated simultaneously. Here, focal mechanism solutions satisfying the following two conditions were searched: (1) $>80 \%$ of the observed P-wave polarities were consistent with the radiation pattern, and (2) $\lambda_{v}$ on the fault planes was smaller than 1 . The number of focal mechanisms obtained was 2,497. The average number of P-wave polarities was 72.6. The P-axes of the obtained focal mechanisms are also shown in Figure 1a. Most of these P-axes are oriented WNW-ESE.

The frequency distributions of $\lambda_{v}$ for four values of $S$ are shown in Figure 2a,d. $\lambda_{v} \sim 0.37$ represents the hydrostatic condition since $\lambda_{v}=1 / \rho$, where $\rho$ is density $\left(2,700 \mathrm{~kg} \mathrm{~m}^{-3}\right)$. The results show that even in the case of the smallest $S(=0.47)$, a significant number of events have $\lambda_{v}$ higher than the hydrostatic pressure. Thus, the diversity of focal mechanisms presently obtained requires overpressured fluids for all the cases of $S$, if we assume $\mu=0.6$.

In order to estimate the spatial distribution of $\lambda_{v}$, we set a grid net spaced $0.005^{\circ}$ horizontally and $0.5 \mathrm{~km}$ vertically and calculated the average value of $\lambda_{v}$ using more than ten events within $2.5 \mathrm{~km}$ horizontally and $1.5 \mathrm{~km}$ vertically from each grid node. The results are shown on the map in Figure 3a and, together with $S$-wave velocity perturbations, on the vertical cross sections in Figure 4 (Okada et al. 2010). In Figure 3a, the $\lambda_{v}$ values were averaged again for the entire depth range. Figure 3a shows that areas with high $\lambda_{v}$ are distributed around the large coseismic slip area near Kurikoma volcano. Figure 4c,d shows that immediately below these regions with high $\lambda_{v}$, a distinct $\mathrm{S}$-wave low-velocity zone is distributed from the mantle wedge further below. This low-velocity zone is connected with the inclined low-velocity zone in the mantle wedge, which probably corresponds to the upwelling flow portion of the mechanically induced secondary convection (Hasegawa and Nakajima 2004). The observations suggest that the high $\lambda_{v}$ in these regions is caused by aqueous fluids supplied from upwelling flow in the mantle wedge. The mainshock rupture also might be closely related with these fluids.

\section{Discussion and conclusions}

In the previous section, we assumed a uniform stress throughout the entire study region. However, stress may change spatially. In order to observe this effect, the entire study area was divided into 20 subareas, as shown in Figure $1 \mathrm{~b}$, and the stress tensor inversion was performed

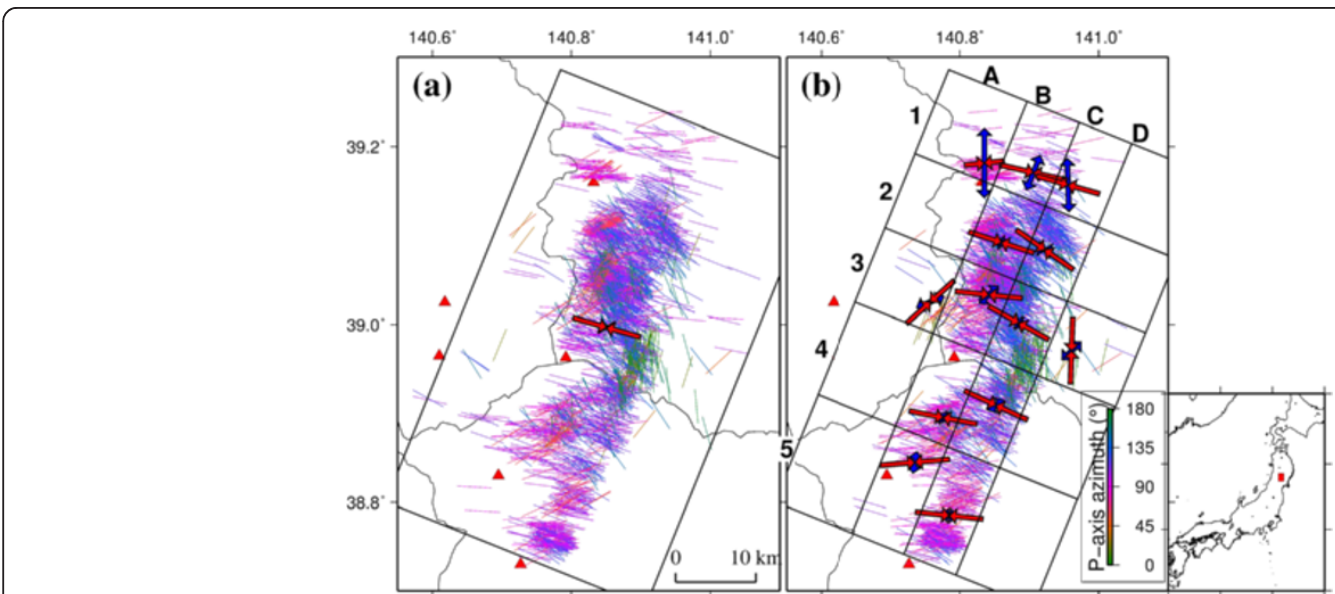

Figure 1 Orientations of best-fit $\sigma 1$ and $\sigma 3$ axes. (a) A uniform stress field across the entire study area and (b) 20 subareas divided along and across the fault strike, shown by black lines. 01 and 03 axes are indicated by red and blue arrows, respectively, at the centroid of events used for the inversions. The length of the arrows indicates the relative plunge of the axes. P-axis orientations are also shown by bars. The length and color (scale is shown at the right) of a bar corresponds to the plunge and azimuth of the P-axes, respectively. 

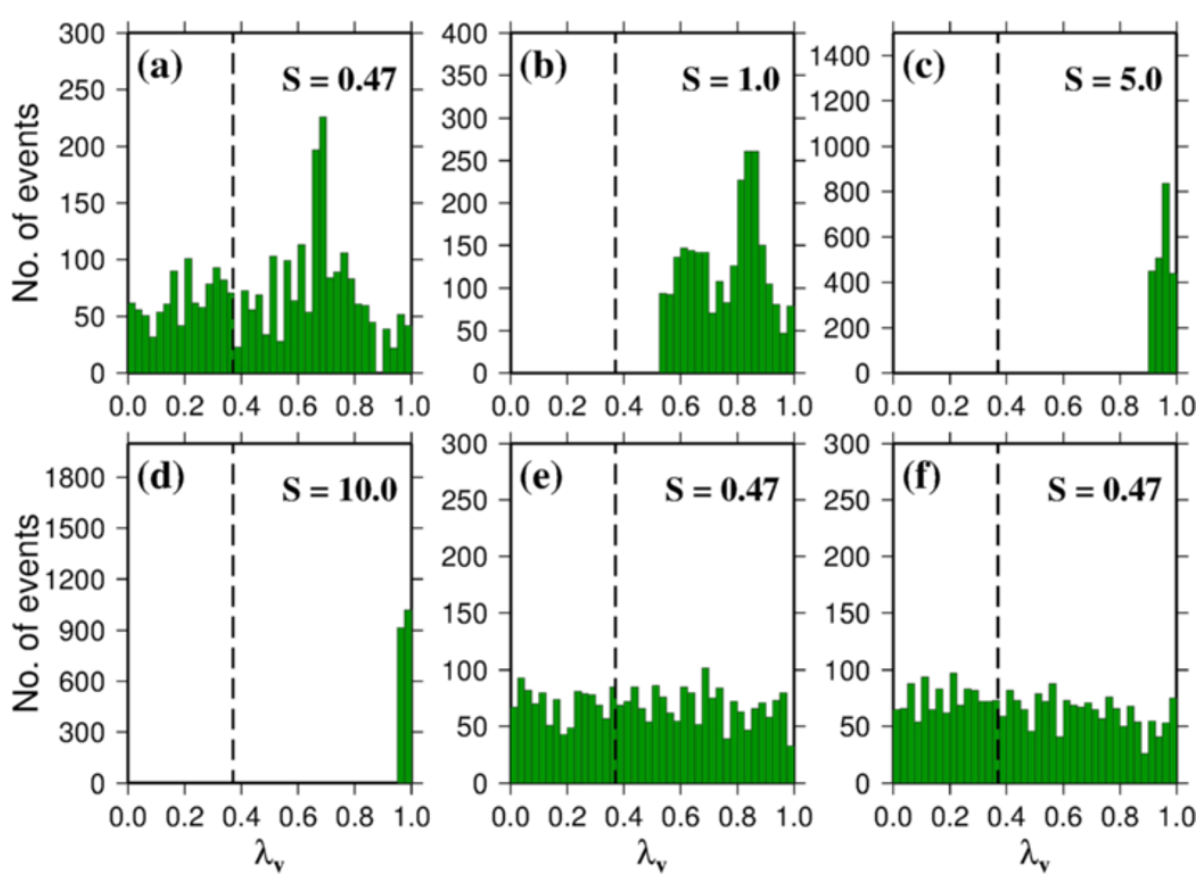

Figure 2 Frequency distributions. $(\mathbf{a}, \mathbf{b}, \mathbf{c}, \mathbf{d})$ Frequency distributions of $\lambda_{v}$ for four values of $S$. Uniform stress in the entire study area is assumed. The dashed line shows $\lambda_{v}=0.37$, corresponding to hydrostatic pressure. (e) Frequency distribution of $\lambda_{v}$ for the case of 20 subareas and $S=0.47$. (f) Frequency distribution of $\lambda_{v}$ for the case of 80 subareas and $S=0.47$.

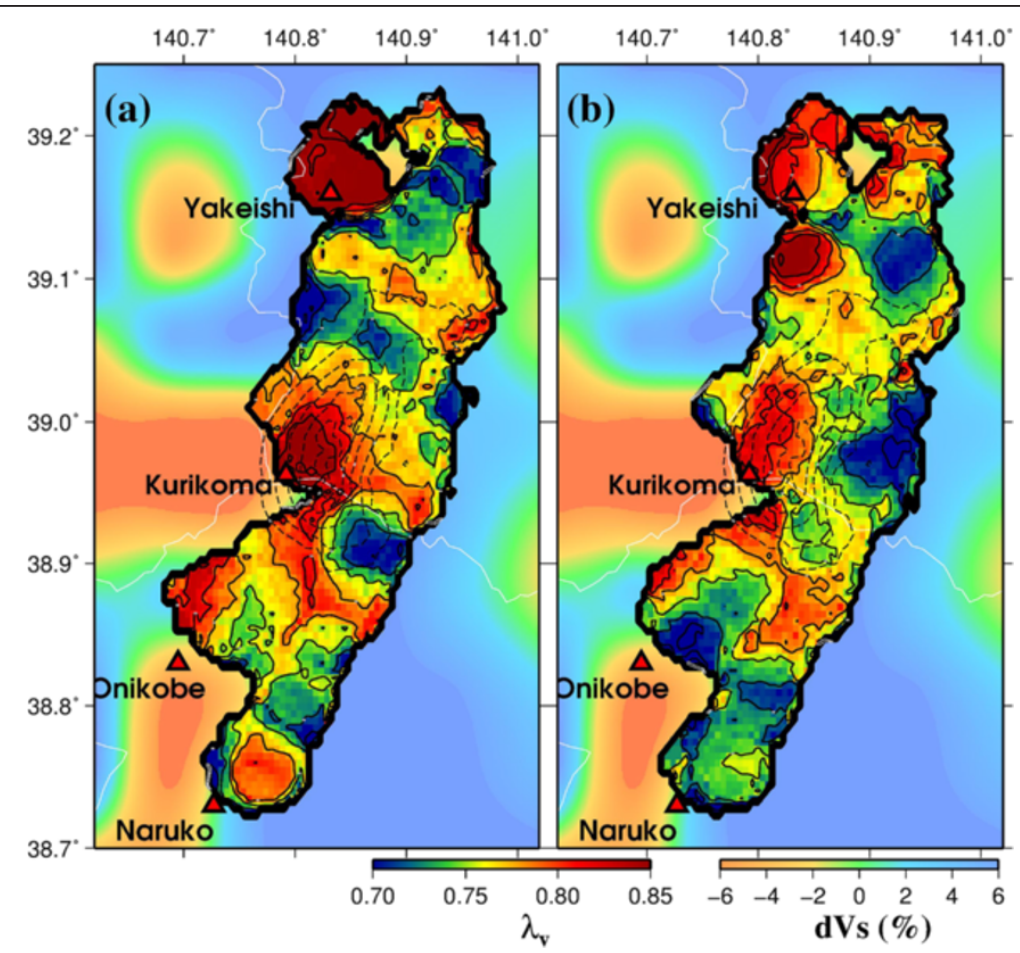

Figure 3 Spatial distribution of $\lambda_{\boldsymbol{v}}$. (a) Uniform stress in the entire area and (b) 20 subareas divided along and across the fault strike. The averaged values of $\lambda_{v}$ are shown by the color scale at the bottom right. The background color shows the S-wave velocity perturbation at a depth of $10 \mathrm{~km}$ (Okada et al. 2010; scale is shown at the bottom left). Broken black contour shows the coseismic slip estimated by linuma et al. (2009). Red triangles denote Quaternary volcanoes. 


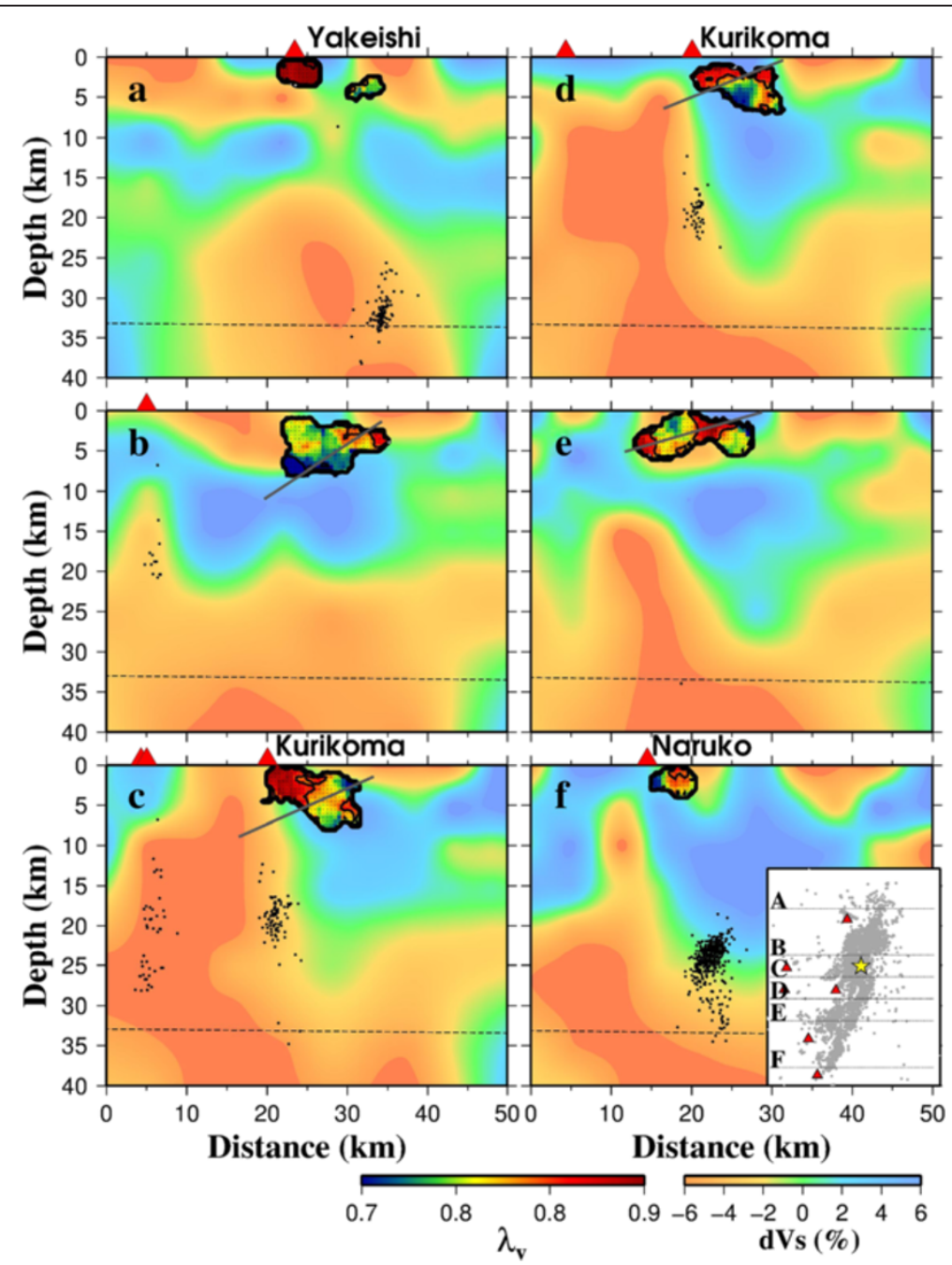

Figure 4 Cross-sectional views of $\lambda_{v}$ for the case of uniform stress. The averaged values of $\lambda_{v}$ are shown by the color scale at the bottom right. The background color shows the S-wave velocity perturbation by Okada et al. (2010) (scale is shown at the bottom left). Locations of cross-sections are shown in the insert map with the label of (a) to (f). The gray lines show the mainshock fault planes by linuma et al. (2009). The thin broken line denotes the Moho discontinuity (Zhao et al. 1990). Black circles show deep low-frequency earthquakes.

for each subarea. Estimated stress orientations are shown in Figure 1b, and their 68\% and 95\% confidence regions are shown in Additional file 2: Figure S2b. Only subareas with more than 15 focal mechanisms are shown. Figure $1 b$ shows that most of the subareas have stress orientations similar to those in Figure 1a. However, some spatial variation of the stress field does exist. In subareas A-3 and $\mathrm{D}-3$, the $\sigma 1$ axis is oriented NE-SW and N-S, respectively, which is significantly different from those of the other subareas. In the northern subareas, A-1, B-1, and C1 , the $\sigma 3$ axis is nearly horizontal, indicating a strike-slip faulting stress regime. Thus, the stress field seems to be somewhat heterogeneous spatially. This means that the diversity of focal mechanisms is produced not only by the difference in frictional strength but also by the heterogeneous stress field.
Frequency distributions of $\lambda_{v}$ for the case of $S=0.47$ are shown in Figure 2e. For the homogeneous stress field shown in Figure 2a,b,c,d, even in the case of the smallest $S(=0.47)$, a fairly large number of events have higher $\lambda_{v}$ than hydrostatic pressure, which requires overpressured fluids if we assume $\mu=0.6$. We estimated the spatial distribution of $\lambda_{v}$ for these spatially heterogeneous stress fields, assuming that $S$ was constant throughout the study area. The results are shown in Figure 3b. The figure shows that the high- $\lambda_{v}$ areas near Kurikoma volcano are still visible in this case, although the spatial distributions differ slightly from Figure 3a.

This tendency of high $\lambda_{v}$ values near Kurikoma volcano remained stable regardless of how the study area was divided. We further divided the study area into four depth ranges of 0 to $2 \mathrm{~km}, 2$ to $4 \mathrm{~km}, 4$ to $6 \mathrm{~km}$, and $>6 \mathrm{~km}$, 
resulting in 80 subvolumes. We applied the stress tensor inversion method to each of the 80 subvolumes. The results (not shown) are similar to those of Figure 3a,b of the above two cases, showing the robustness of the estimated high $\lambda_{v}$ values near Kurikoma volcano. The frequency distribution of $\lambda_{v}$ for $S=0.47$ is shown in Figure 2f. Again, a considerable number of events have higher $\lambda_{v}$ than hydrostatic pressure, requiring overpressured fluids.

Even if stress orientation and frictional strength are uniform, some diversity of focal mechanism can be explained by the heterogeneity of stress magnitudes. Additional file 3: Figure S3 and Additional file 4: Figure S4 show the distributions of $S$ under the assumption of uniform stress orientation and constant apparent frictional coefficient $\mu^{\prime}=\mu\left(1-\frac{P}{\sigma_{n}}\right)=0.4$. The spatial pattern of $S$ is similar to that of $\lambda_{v}$ in Figure 3, which means that lower $S$, as well as higher $\lambda_{v}$, may explain the slip on badly oriented faults. However, the figure also shows that most of the region had very small $S$ values, indicating a stress state far exceeding the critical stress state. Although we cannot discriminate which of the two causes the diversity of focal mechanism, we prefer heterogeneity of fault strengths, as described.

In conclusion, focal mechanisms and the stress field in the focal region of the 2008 Iwate-Miyagi Nairiku earthquake were simultaneously estimated by inverting P-wave polarity data obtained from very dense seismic networks for aftershock observation and other surrounding temporarily and routinely operated stations. The pore fluid pressure ratio was calculated at each earthquake fault from the obtained stress field and the fault plane orientation. Assuming a uniform stress field, the diversity of focal mechanisms requires pore pressures at many of those fault planes higher than hydrostatic pressure. The spatially averaged distribution of pore pressure ratio shows that areas with high pore pressure ratio are distributed around the large coseismic slip area near Kurikoma volcano. Immediately below these regions of high pore pressure ratio, there exists a distinct seismic low-velocity zone that continues down to the mantle wedge below. The present observations suggest that crustal fluids supplied from the mantle wedge cause high pore pressure ratio in the source area near Kurikoma volcano.

\section{Additional files}

Additional file 1: Figure S1. Locations of seismic stations and earthquakes. Crosses represent stations: black shows the permanent stations of NIED, JMA, and Tohoku University; blue shows the temporary stations by JNES; and red shows the temporary stations of the aftershock observation. Beachball represents the mainshock focal mechanism. Gray circles show the aftershocks. Contours show the coseismic slip estimated by linuma et al. (2009).
Additional file 2: Figure S2. Equal-area lower hemisphere stereo plots of the $\sigma 1$ and $\sigma 3$ axes for each grid node for the case of (a) uniform stress in the entire study area and (b) 20 subareas divided along and across the fault strike. Circles and squares show the $\sigma 1$ and $\sigma 3$ axes, respectively. Black indicates the best-fit solutions. Dark gray and light gray indicate the $95 \%$ and $68 \%$ confidence regions, respectively.

Additional file 3: Figure S3. (a-d) Frequency distributions of $S$ for four values of $\mu^{\prime}$. A constant apparent frictional coefficient is assumed in the entire study area. (e) Frequency distributions of $S$ for the case of 20 subareas and $\mu^{\prime}=0.1$. (f) Frequency distributions of $S$ for the case of 80 subareas and $\mu^{\prime}=0.1$.

Additional file 4: Figure S4. Spatial distribution of $S$ for the case of (a) uniform stress in the entire area and (b) 20 subareas divided along and across the fault strike $\left(\mu^{\prime}=0.4\right)$. The averaged values of $S$ are shown by the color scale at the bottom right. The background color shows the S-wave velocity perturbations at a depth of $10 \mathrm{~km}$ (Okada et al. 2010; scale is shown at the bottom left). Broken black contour shows the coseismic slip estimated by linuma et al. (2009). Red triangles denote Quaternary volcanoes.

\section{Competing interests}

The authors declare that they have no competing interests.

\section{Authors' contributions}

$\mathrm{KY}$ analyzed the data, participated in the temporary observations, and drafted the manuscript. AH and TO served as scientific advisors. HT, MK, TI, YY, HK, YI, AK, TM, HM, and YA participated in the temporary observations. All authors read and approved the final manuscript.

\section{Acknowledgements}

We are thankful to G. Abers for allowing us to use the MOTSI code. We would like to thank the editor (Hiroaki Toh) and two anonymous reviewers for their helpful comments. We used the data observed by the Group for aftershock observations of the Iwate-Miyagi Nairiku earthquake of 2008 and by the Japan Nuclear Energy Safety Organization. This study was partly supported by the Global Education and Research Center for Earth and Planetary Dynamics, Global COE Program, at Tohoku University, and by the Scientific Research Program on Innovative Areas, 'Geofluids: Nature and of Fluids in Subduction Zones,' at the Tokyo Institute of Technology. KY is grateful for the support from the Japan Society for the Promotion of Science (JSPS).

\section{Author details}

${ }^{1}$ Research Center for Prediction of Earthquakes and Volcanic Eruptions, Graduate School of Science, Tohoku University, 6-6 Aza-Aoba, Aramaki, Aoba-ku, Sendai 980-8578, Japan. ${ }^{2}$ Institute of Seismology and Volcanology, Graduate School of Science, Hokkaido University, Sapporo 060-0810, Japan. ${ }^{3}$ Graduate School of Science and Technology, Hirosaki University, Hirosaki 036-8561, Japan. ${ }^{4}$ Earthquake Research Institute, University of Tokyo, Tokyo 113-0032, Japan. ${ }^{5}$ Earthquake and Volcano Research Center, Graduate School of Environmental Studies, Nagoya University, Nagoya 464-8601, Japan. ${ }^{6}$ Disaster Prevention Research Institute, Kyoto University, Uji 611-0011, Japan. ${ }^{7}$ Kochi Earthquake Observatory, Faculty of Science, Kochi University, Kochi 780-8072, Japan. ${ }^{8}$ Institute of Seismology and Volcanology, Faculty of

Sciences, Kyushu University, Shimabara 855-0843, Japan. ${ }^{9}$ Graduate School of Science and Engineering, Kagoshima University, Kagoshima 890-0064, Japan.

${ }^{10}$ National Institute for Earth Science and Disaster Prevention, Tsukuba 305-0006, Japan.

Received: 28 March 2014 Accepted: 9 June 2014

Published: 20 June 2014

\section{References}

Abers GA, Gephart JW (2001) Direct inversion of earthquake first motions for both the stress tensor and focal mechanisms and application to southern California. J Geophys Res 106:26523-26540

Brudy M, Zoback MD, Fuchs K, Rummel F, Baumgartner J (1987) Estimation of the complete stress tensor to $8 \mathrm{~km}$ depth in the KTB scientific drill holes: implications for crustal strength. J Geophys Res 102:18453-18475 Byerlee J (1978) Friction of rocks. Pure Appl Geophys 116:615-626 
Gephart JW, Forsyth DW (1984) An improved method for determining the regional stress tensor using earthquake focal mechanism data: application to the San Fernando earthquake sequence. J Geophys Res 89:9305-9320

Hasegawa A, Nakajima J (2004) Geophysical constraints on slab subduction and arc magmatism. In: Sparks RSJ, Hawkesworth CJ (ed) The state of the planet: frontiers and challenges in Geophysics, AGU Geophysical Monograph 150, IUGG, vol 19. AGU, Washington, D.C., pp 81-94

Hasegawa A, Umino N, Takagi A (1978) Double-planed structure of the deep seismic zone in the northeastern Japan arc. Tectonophysics 47:43-58

Hasegawa A, Horiuchi S, Umino N (1994) Seismic structure of the northeastern Japan convergent margin: a synthesis. J Geophys Res 99:22295-22311

linuma T, Ohzono M, Ohta Y, Miura S, Kasahara M, Takahashi H, Sagiya T, Matsushima T, Nakao S, Ueki S, Tachibana K, Sato T, Tsushima H, Takatsuka K, Yamaguchi T, Ichiyanagi M, Takada M, Ozawa K, Fukuda M, Asahi Y, Nakamoto M, Yamashita Y, Umino N (2009) Aseismic slow slip on an inland active fault triggered by a nearby shallow event, the 2008 Iwate-Miyagi Nairiku earthquake (Mw6.8). Geophys Res Lett 36, L20308

Leclère H, Daniel G, Fabbri O, Cappa F, Thouvenot F (2013) Tracking fluid pressure buildup from focal mechanisms during the 2003-2004 Ubaye seismic swarm, France. J Geophys Res 118:4461-4476

Michael AJ (1987) Use of focal mechanisms to determine stress: a control study. J Geophys Res 92:357-368

Okada T, Umino N, Hasegawa A, Group for the aftershock observations of the Iwate-Miyagi Nairiku Earthquake in 2008 (2012) Hypocenter distribution and heterogeneous seismic velocity structure in and around the focal area of the 2008 Iwate-Miyagi Nairiku Earthquake, NE Japan—-possible seismological evidence for a fluid driven compressional inversion earthquake. Earth Planets Space 64:717-728

Okada T, Umino N, Hasegawa A (2010) Deep structure of the Ou mountain range strain concentration zone and the focal area of the 2008 Iwate-Miyagi Nairiku earthquake, NE Japan - seismogenesis related with magma and crustal fluid. Earth Planets Space 62:1-6

Rivera L, Kanamori H (2002) Spatial heterogeneity of tectonic stress and friction in the crust. Geophys Res Lett 29:1088

Terakawa T, Matsu'ura M (2010) The 3-D tectonic stress fields in and around Japan inverted from centroid moment tensor data of seismic events. Tectonics 29, TC6008

Terakawa T, Zoporowski A, Galvan B, Miller SA (2010) High pressure fluid at hypocentral depths in the L'Aquila region inferred from earthquake focal mechanisms. Geology 38(11):995-998

Terakawa T, Miller SA, Deichmann N (2012) High fluid pressure and triggered earthquakes in the enhanced geothermal system in Basel, Switzerland. J Geophys Res 117, B07305. doi:10.1029/2011JB008980

Yoshida K, Hasegawa A, Okada T, linuma T, Ito Y, Asano Y (2012) Stress before and after the 2011 Great Tohoku-Oki earthquake and induced earthquakes in inland areas of eastern Japan. Geophys Res Lett 39, L03302

Zhao D, Horiuchi S, Hasegawa A (1990) 3-D seismic wave velocity structure of the crust in the northeastern Japan arc. Tectonophysics 181:135-149

Zoback MD, Healy JH (1992) In situ stress measurements to $3.5 \mathrm{~km}$ depth in the Cajon Pass scientific research borehole: implications of the mechanisms of crustal faulting. I Geophys Res 97:5039-5057

doi:10.1186/1880-5981-66-59

Cite this article as: Yoshida et al: Pore pressure distribution in the focal region of the 2008 M7.2 Iwate-Miyagi Nairiku earthquake. Earth, Planets and Space 2014 66:59.

\section{Submit your manuscript to a SpringerOpen ${ }^{\circ}$ journal and benefit from:}

- Convenient online submission

- Rigorous peer review

- Immediate publication on acceptance

- Open access: articles freely available online

- High visibility within the field

- Retaining the copyright to your article

Submit your next manuscript at $\gg$ springeropen.com 